\title{
Fundamentos e Introdução à Análise Sensorial
}

Michelle Barboza Nogueira

https://doi.org/10.4322/mp.978-65-994457-0-5.c1

\section{Resumo}

As características sensoriais dos alimentos representam um critério determinante na escolha de um produto por parte dos consumidores, e reflete diretamente nas medidas tomadas e tecnologias aplicadas por parte da indústria alimentícia. Este capítulo objetiva apresentar aos leitores os fundamentos básicos necessários para o entendimento da aplicação de métodos sensoriais na avaliação dos mais diferentes alimentos, situando o profissional de alimentos quando atuante nesta área do conhecimento. As principais terminologias utilizadas e aplicações da análise sensorial permitem compreender sua importância, assim como a elucidação dos mecanismos humanos de percepções sensoriais esclarecem de que forma os órgãos dos sentidos atuam como instrumentos de medição e avaliação, sendo capazes de fornecer respostas importantes acerca das características dos alimentos. Para a realização de testes baseados em métodos sensoriais é necessário também saber as condições estruturais requeridas, a maneira correta de preparo e apresentação das amostras, e quais são os critérios que um indivíduo deve apresentar para tornar-se um julgador em uma equipe de análise sensorial.

Palavras-chave: julgadores, órgãos dos sentidos, percepção, receptores, testes.

\section{Introdução}

A análise sensorial constitui uma importante área da Ciência e Tecnologia de Alimentos que permite, a partir das percepções sensoriais, avaliar as características dos mais variados produtos alimentícios, utilizando os seres humanos como instrumento de medição [1].

As características sensoriais dos alimentos, como aparência, aroma, sabor e textura refletem diretamente na intenção de adquirir e/ou consumir ou não um produto pelos consumidores. Portanto a indústria alimentícia trabalha 
no sentido de encontrar instrumentos para identificar $e$ atender às características desejadas pelos consumidores, cada vez mais exigentes, em um mercado de grande competitividade no qual se encontra inserida [2, 3].

A avaliação sensorial é aplicada com inúmeras finalidades, entre as quais pode-se citar a avaliação do efeito de alterações no processamento, seleção de matérias-primas ou diferentes ingredientes no desenvolvimento de um novo produto, avaliação da qualidade das características como sabor, textura e cor de um produto, bem como sua estabilidade durante 0 armazenamento. De forma geral, uma equipe de julgadores é selecionada para analisar sensorialmente os alimentos, com finalidades específicas, através da utilização de testes sensoriais que geram respostas. Estas irão auxiliar os avaliadores a tomarem decisões quanto aos produtos produzidos, de acordo com os objetivos que desejam alcançar com relação ao público consumidor [4].

Conhecer os conceitos base de uma ciência constitui um ponto fundamental para o entendimento de suas particularidades e aplicações. Diante disso, o objetivo deste capítulo é abordar os principais fundamentos de análise sensorial de alimentos, servindo de base para sua correta aplicação na realização dos diferentes métodos sensoriais.

Assim, este capítulo abordará as principais definições e aplicações da análise sensorial, os mecanismos de percepção através dos órgãos dos sentidos humanos e as condições estruturais, das amostras e dos julgadores para que as avaliações dos alimentos sejam realizadas corretamente.

\section{Definições e Aplicações da Análise Sensorial de Alimentos}

Análise sensorial de alimentos pode ser definida como uma ferramenta científica fundamentada em um conjunto de técnicas e métodos baseados nas propriedades sensoriais dos alimentos percebidas pelos órgãos dos sentidos. Esta ferramenta possibilita a percepção, análise, identificação e interpretações das reações obtidas a partir da visão, do tato, do paladar, da audição e do olfato $[5,6]$.

Segundo Dutcosky [1], a análise sensorial é uma ciência quantitativa, fato que permite medir a percepção humana em relação às características sensoriais dos produtos alimentícios, a partir da coleta de informações e sua transformação em dados numéricos. Além disso, tais dados coletados a partir 
de delineamentos experimentais bem elaborados são analisados com métodos estatísticos adequados que permitem sua interpretação, sendo importantes dentro do contexto das hipóteses e do conhecimento prévio de suas implicações para tomadas de decisão pela indústria de alimentos e/ou por pesquisadores.

Para a Ciência e Tecnologia de Alimentos, a análise sensorial representa o campo científico que serve como ferramenta fundamental para a determinação da qualidade de um produto desenvolvido ou modificado. Desta maneira Dutcosky [1] e Gularte [6] apresentam inúmeras aplicações, tanto para a indústria de alimentos quanto para instituições de pesquisa, as quais se citam a continuação:

- No desenvolvimento de novos produtos, permitindo avaliar e selecionar matérias-primas, estudar sua estabilidade durante o armazenamento e auxiliar na determinação seu prazo de validade, identificar a aceitação e intenção de compra de um produto alimentício, comparar com produtos concorrentes do mercado;

- $\mathrm{Na}$ alteração de formulações ou forma de processamento tecnológico sobre um produto alimentício, verificando o efeito de diferentes matériasprimas, troca de ingredientes e variação de suas quantidades, ou até mesmo para verificar se a troca de fornecedores afeta as características do produto final;

- Na busca pela redução de custos ao produzir um produto, verificando se a aplicação de processos menos onerosos, a produção em local ou equipamento diferente e substituição de ingredientes de preço mais baixo, avaliando o efeito das modificações;

- Identificação de atributos sensoriais, ordem de percepções humanas e sua intensidade, bem como a definição de quantidades mínimas e máximas de um determinado ingrediente capaz de produzir determinado efeito;

- Avaliação da qualidade de um alimento processado ou não processado;

- Controle do progresso durante o desenvolvimento de um produto, fornecendo dados tanto qualitativos quanto quantitativos de suas propriedades sensoriais; 
- Controle do efeito de diferentes embalagens sobre produtos acabados;

- Testes de mercado, onde pode ser definido o público alvo para cada produto, a preferência e/ou a aceitabilidade como consequência do aspecto sensorial do alimento percebido pelos consumidores, fornecendo dados sobre o impacto emocional que um determinado produto exerce sobre o consumidor ou um nicho específico;

Diante disso, percebe-se a importância e aplicabilidade da análise sensorial, podendo-se inferir que a mesma pode auxiliar as empresas do setor alimentício, tanto de forma direta quanto indireta, fornecendo suporte técnico para pesquisa, industrialização, controle de qualidade, estratégia de negócio ou marketing de um determinado produto ou de uma marca, e até mesmo na monitorização da concorrência entre produtos e empresas [7].

Para uma boa compreensão dos fundamentos da Análise Sensorial de Alimentos e sua constante evolução, aliada aos avanços científicos a ABNT (Associação Brasileira de Normas Técnicas) publicou nos últimos anos atualizações de normas técnicas baseadas em normas ISO (International Organization for Standardization), entre as quais se inclui a norma para terminologias de Análise Sensorial, ISO 5492 [8], relativas aos órgãos dos sentidos seguidas de suas definições, entre as quais cita-se as de maior relevância:

- Receptor: parte específica de um órgão dos sentidos que responde a um estímulo particular;

- Percepção: consciência dos efeitos de um único ou múltiplos estímulos sensoriais;

- Estímulo: aquilo que estimula um receptor;

- Sensação: reação psicofisiológica resultante da estimulação sensorial;

- Sensibilidade: habilidade de perceber, identificar e/ou diferenciar, qualitativa e/ou quantitativamente, um ou mais estímulos por meio dos órgãos dos sentidos;

- Fadiga sensorial: forma de adaptação sensorial na qual ocorre uma diminuição na sensibilidade; 
- Intensidade: magnitude de uma sensação percebida, ou magnitude de um estímulo que causa a sensação percebida;

- Mascaramento: fenômeno onde a qualidade dentro de uma mistura mascara ou encobre uma ou várias outras qualidades presentes.

Outras normas técnicas trazem importantes informações acerca da Análise Sensorial de Alimentos incluindo temáticas como orientações para treinamento de avaliadores, metodologias para estabelecer perfil sensorial e ambiente de testes. Ao todo existem 17 normas em vigor no Brasil nesta área do conhecimento, entre as quais 14 delas são normas de adoção da ISO.

\section{1. Órgãos dos sentidos e suas percepções}

A expressão "sensorial" deriva de "sentido", originário da palavra "sensus". A anatomia humana, dotada de órgãos como olhos, ouvidos, língua, mãos e nariz, possibilita com que os indivíduos utilizem os sentidos para a percepção sensorial através de estruturas responsáveis por receber informações de estímulos, denominadas receptores sensoriais localizados em cada um desses órgãos. Tais estímulos podem ser tanto químicos quanto físicos, como por exemplo a presença de uma substância química no alimento ou a pressão da pelo exercida no alimento, respectivamente, sendo captados pelos receptores e traduzidos em forma de resposta [9].

Conforme Gularte [6] existem classes de estímulos como elétrico, mecânico, fótico, térmico, acústico ou químico, e para que a resposta aconteça é necessário que pelo menos um destes estímulos chegue aos receptores dos diferentes órgãos dos sentidos. Segundo Bento, Andrade e Silva [9], cada estímulo ao chegar a um receptor específico causa um impulso nervoso em uma corrente de neurônios do sistema nervoso, resultando na informação traduzida a partir das sensações que cada indivíduo tem ao consumir um dado alimento. Ou seja, a sensação ou reconhecimento, que pode ser denominado pelo termo "percepção" é quem permite sua tradução a partir da verbalização das características percebidas pelo indivíduo. Tal mecanismo pode ser observado de forma resumida e esquemática na Figura 1. 


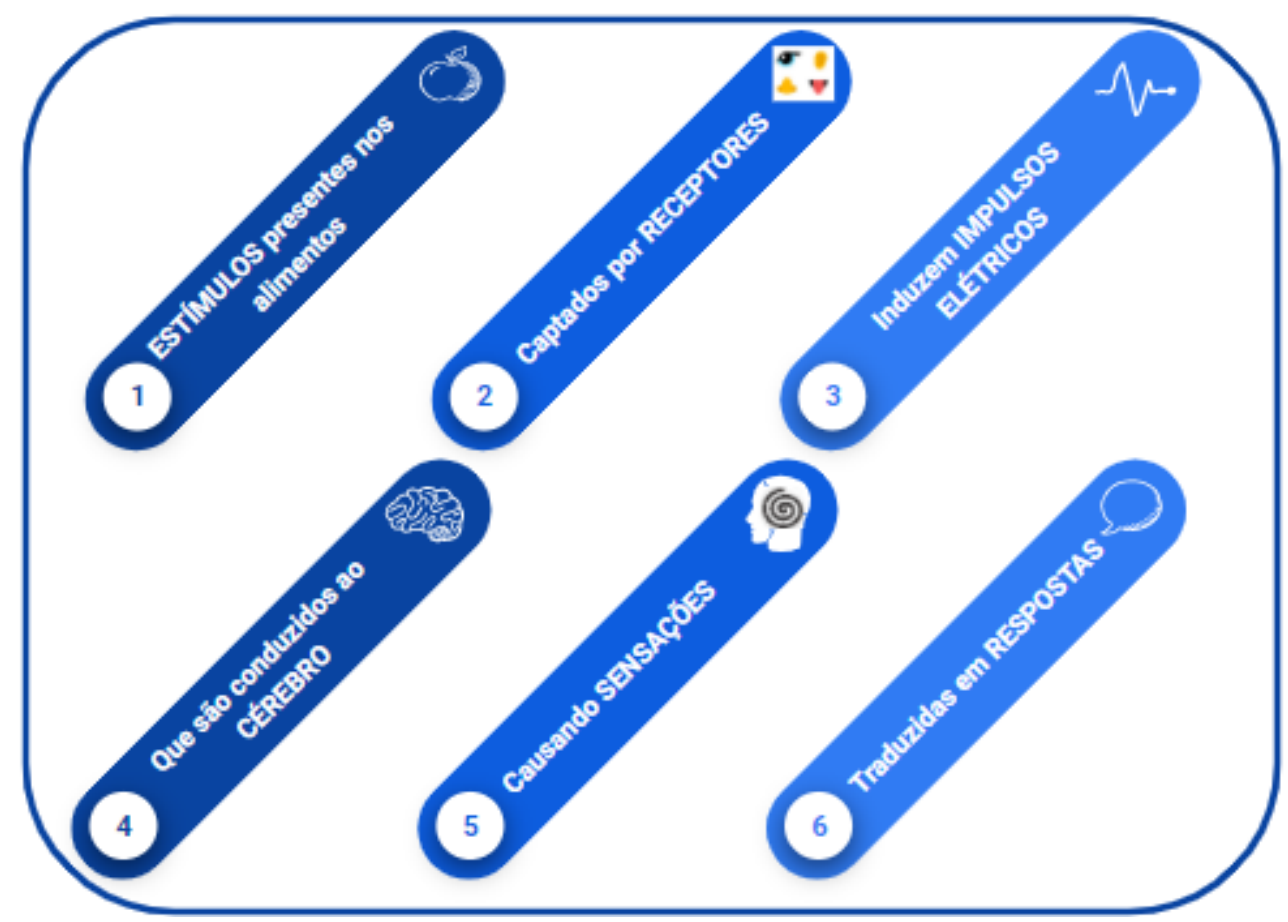

Figura 1. Condução do estímulo sensorial desde o alimento até a tradução da percepção. Adaptado de Bento, Andrade e Silva [9]

De acordo com a ISO 5492 [8] a percepção pode ser definida como o reconhecimento da sensação, baseada na memória e na experiência do indivíduo, resultante da agregação de informações dos órgãos dos sentidos, ou seja, é a tomada de consciência de estímulos sensoriais únicos ou múltiplos.

Considerando que a capacidade de percepção dos seres humanos varia e apresenta limitações de sensibilidade, torna-se importante mencionar o conceito de limiar [10]. Para Análise Sensorial, os limiares de maior relevância são o limiar de detecção, o limiar de reconhecimento, o limiar diferencial e o limiar de saturação, e todas estas terminologias são conceituados na ISO 5492 [8], especificadas na Tabela 1. 
Tabela 1. Terminologias dos limiares importantes para Análise sensorial de Alimentos e suas definições conforme a ISO 5492 [8].

\begin{tabular}{cc}
\hline Terminologia & Definição \\
\hline $\begin{array}{c}\text { Limiar de } \\
\text { detecção }\end{array}$ & $\begin{array}{c}\text { Valor mínimo de um estímulo sensorial } \\
\text { necessário ao aparecimento de uma } \\
\text { sensação (que poderá ainda não ser } \\
\text { identificada). }\end{array}$ \\
$\begin{array}{c}\text { Limiar de } \\
\text { reconhecimento }\end{array}$ & $\begin{array}{c}\text { Valor mínimo de um estímulo sensorial } \\
\text { que permite identificar a sensação } \\
\text { percebida. }\end{array}$ \\
Limiar & $\begin{array}{c}\text { Valor mínimo da alteração de um } \\
\text { estímulo necessário para que a } \\
\text { diferencial }\end{array}$ \\
& alterado) seja percetível. \\
Limiar de & $\begin{array}{c}\text { Valor mínimo de um estímulo sensorial } \\
\text { intenso acima do qual deixa de haver } \\
\text { diferença perceptível na intensidade } \\
\text { percebida. }\end{array}$ \\
&
\end{tabular}

Os limiares são importantes para definir o ponto de transição entre a possibilidade de um indivíduo perceber ou não um determinado estímulo.

\subsubsection{Sentido Gustativo}

A língua é o principal órgão dos sentidos, a qual é responsável pela detecção do gosto de um alimento. O sentido gustativo atua através do estímulo que substâncias químicas solúveis gerados ao excitar os receptores, denominados papilas gustativas [4, 11]. As papilas contém em média 250 gemas gustativas onde encontram-se as células receptoras, que são responsáveis pela percepção do gosto [6], causado pelas sensações gustativas básicas: doce, salgado, ácido, amargo e umami [11].

É importante mencionar que a língua concentra a maior parte dos receptores sensoriais do paladar, porém, os mesmos podem ser encontrados em menor quantidade nas amígdalas, na epiglote, na garganta, nas bochechas, na superfície inferior da boca, no palato duro, na mucosa dos lábios e no esôfago [6, 9]. 
A ordem de detecção dos gostos básicos é comumente justificada pela localização dos receptores na língua, como pode ser observado na Figura 2 [11]. Desta forma, o gosto doce normalmente é a primeira sensação transmitida ao cérebro, seguido do salgado, ácido, metálico e amargo. Existem autores que retiram o metálico da classificação dos gostos sob a justificativa que o metálico é definido como uma sensação olfatória-gustativa, e não apenas um gosto [1, $11]$.

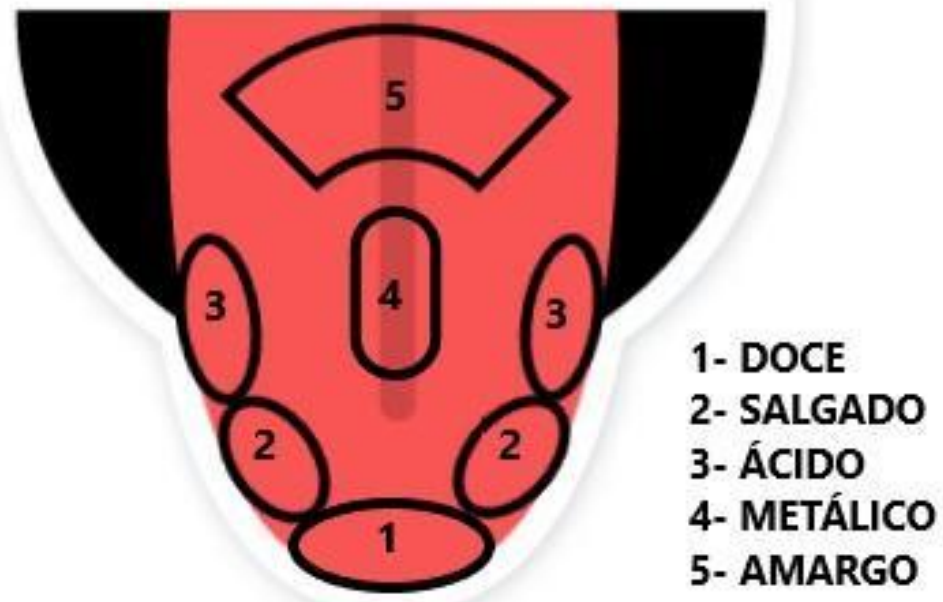

Figura 2. Localização dos receptores sensoriais nas regiões da língua humana encontrados em maior quantidade.

Apesar disso, é sabido que cada papila gustativa apresenta diferentes graus de detecção de todos os gostos primários, sendo predominantes células receptoras especificadas com sensibilidade maior para cada gosto em cada região da língua. O gosto umami, caracterizado pela percepção da substância química "glutamato monossódico" normalmente tem a maior parte de seus receptores concentrados no centro da língua [11].

O sabor é uma experiência mista, porém unitária, percebida pelos sentidos da gustação em conjunto com a olfação, influenciado também pelos efeitos táteis, térmicos e cinestésicos durante a degustação de um alimento [6].

Oliveira [12], indica que vários fatores podem interferir nas avaliações olfativas. É o caso de patologias desenvolvidas em função do uso de fármacos, causadas por acidentes, ou até mesmo por fatores genéticos, como por exemplo: 
- Ageusia: Deficiência de sensibilidade aos estímulos gustativos podendo ser total ou parcial, temporária ou permanente.

- Hipogeusia: Decréscimo da sensibilidade do gosto.

- Parageusia: Alteração na sensibilidade do gosto (troca de sabores).

- Hipergeusia: Acuidade excessiva ou aumentada da percepção do gosto.

\subsubsection{Sentido Olfativo}

O nariz é o órgão físico que proporciona o sentido do olfato, permitindo que os indivíduos possam sentir o odor ou o aroma dos alimentos [6, 9] infere que 0 odor e o aroma são atributos sensoriais perceptíveis tanto por sensações olfativas quanto nasais. Os odores são produzidos por misturas complexas de moléculas odoríferas e, no instante em que substâncias voláteis presentes nos alimentos se desprendem, estando em fase gasosa, passando pelas narinas e acarretando no estímulo de quimiorreceptores olfativos, permitindo a percepção dos odores. De acordo com Oliveira [12], a percepção dos odores está sujeita a variação por fadiga e adaptação dos receptores olfativos. Já o aroma é uma sensação percebida exclusivamente durante a mastigação pela via retronasal [6].

Para que a percepção dos odores ou aromas aconteça é indispensável que as moléculas voláteis sejam solúveis na mucosa olfatória e que sua concentração se encontre acima do limiar de percepção do indivíduo. O sistema olfativo é composto inicialmente pela mucosa nasal, onde encontramse milhares de receptores, pelo epitélio olfatório que possui células ciliadas onde estão contidas cerca de 3 milhões de células receptoras. Na sequência, os impulsos olfatórios são transmitidos pelo nervo olfatório e chegam até cérebro humano através do bulbo olfatório [6].

De acordo com o Instituto Adolfo Lutz [13], o bulbo olfativo apresenta conexão direta com um "banco de dados" presente no cérebro, responsável pelo armazenamento das memórias dos odores sentidos ao longo da vida por cada indivíduo. Funciona como um sistema "chave-fechadura", de modo que quando uma informação chega ao cérebro, imediatamente é comparada com os padrões conhecidos por aquela pessoa, e quando apresenta compatibilidade acontece o encaixe, como ocorre com uma chave em sua fechadura, acontecendo o reconhecimento [13]. 
É possível acontecer o caso de um estímulo odorífero não ser localizado, tanto pelo fato de o indivíduo nunca ter sentido determinado odor quanto pela perda de memória da informação. Desta forma, pode-se dizer que determinado odor não é localizado no "banco de dados" pois não está gravado na memória. Quando isso acontece, as conexões nervosas tendem a registrar o novo odor conforme suas características, de forma a gerar uma nova memória [14]. O ser humano apresenta a capacidade de distinguir entre 2000 e 4000 diferentes impressões olfativas [6].

Uma questão importante a ser considerada sobre o sentido do olfato é possibilidade de adaptação ou fadiga olfatória, que ocorre quando muitas aspirações são feitas, por estimulação prolongada, em que um odor vai ficando mais fraco e o indivíduo pode deixar de percebê-lo. Também pode ocorrer no caso de sentir um odor mais fraco após ter aspirado um odor mais forte. No entanto, em indivíduos fisiologicamente normais, a fadiga olfatória dura em torno de 30 segundos, possibilitando a restauração da sensibilidade. Sugere-se que, ao analisar diferentes amostras em que deseja-se avaliar o odor, utiliza-se da técnica de "cheirar" café ou a pele do próprio pulso [9].

De acordo com Olineira [12] existem inúmeros fatores que podem interferir na avaliação sensorial olfativa, entre as quais é possível citar:

- Anosmia: Deficiência de sensibilidade aos estímulos olfativos, podendo ser total ou parcial, temporária ou permanente.

- Cacosmia: Percepção permanente de odores desagradáveis.

- Heterosmia: Troca de odores.

- Hiperosmia: Aumento de sensibilidade para um ou vários estímulos olfativos.

- Hiposmia: Redução de sensibilidade para um ou vários estímulos olfativos.

\subsubsection{Sentido Visual}

Os órgãos físicos que permitem ao ser humano o sentido da visão são os olhos, obtendo, através deles as primeiras impressões de um alimento a ser consumido sobre sua aparência de uma forma geral [9]. Aspectos do produto alimentício como a cor, a textura da superfície, o brilho, a forma e o tamanho 
são características percebidas pela visão que ajudam o consumidor a decidir se deseja ou não consumi-lo [6].

O olho humano pode ser definido como um órgão fotorreceptor, pois a visão é um complexo fenômeno baseado na incidência de sinais luminosos sobre a retina, através da identificação da luz, das cores, do brilho e das formas dos alimentos. A retina contém dois tipos de células: os cones e os bastonetes, que funcionam como receptores e totalizam cerca de 130 milhões de receptores luminosos. Os cones são responsáveis pela detecção da cor, enquanto os bastonetes permitem visualizar a forma e cor escura [12].

Quando um sinal luminoso incide sobre os receptores da retina, provocam alterações que geram estímulos na forma de impulsos elétricos. Estes são conduzidos pelo nervo e o trato ópticos até o cérebro, onde a sensação visual é percebida e traduzida, fornecendo uma resposta [6]

Um indivíduo fisiologicamente normal é capaz de perceber as cores quando a energia radiante da região visível do espectro atinge a retina, ou seja, entre os comprimentos de onda de 380 a 760 nm [13]. No que diz respeito à cor, o indivíduo é capaz de avaliar características como a intensidade, a saturação, a vivacidade, o brilho e o tom. Quanto à aparência, pode identificar características como formatos e tipos de contorno [6].

Como a aparência geral do produto é o parâmetro que exerce maior influência sobre a decisão de compra e consumo de um determinado alimento, as indústrias de alimentos têm priorizado o aspecto visual como critério para torná-lo mais atrativo, incluindo o desenvolvimento de embalagens. Além disso, o sentido da visão, ao gerar uma resposta do indivíduo sobre um produto alimentício, pode estimular outras respostas sensoriais, como o aumento da salivação, ao perceber uma aparência agradável [9].

Existem fatores que podem interferir nas avaliações visuais, como é o caso da discromatopsia, que é uma anomalia na visão, caracterizada pela baixa discriminação das cores. Essa anomalia pode ser causada por fadiga ocular, iluminação não uniforme, cor do ambiente, julgamento dos avaliadores e a falta de uniformidade nas avaliações. Além disso, indivíduos que sofrem de daltonismo não apresentam a capacidade de distinguir algumas cores e tonalidades [12]. Segundo Dutcosky [1], cerca de $8 \%$ dos homens e 0,6\% das mulheres são daltônicos. 


\subsubsection{Sentido Táctil}

O sentido do tato é importante na Análise Sensorial de Alimentos visto que fornece informações sobre consistência, textura, forma, temperatura e peso de um produto alimentício através das percepções geradas pelas mãos e pela boca. A avaliação se dá pelo reconhecimento das características sensoriais através do contato direto com a pele ou através da sensibilidade cutânea [13].

A ISO 5492 [8] que define a norma para terminologias de Análise Sensorial relativas aos órgãos dos sentidos, fornece conceituações importantes sobre terminologias deste sentido, como:

- Táctil: qualquer um dos sentidos cujos receptores estão na pele ou imediatamente abaixo dela (ou nas membranas das mucosas), resultando na percepção do contato, pressão, calor, frio ou dor;

- Somestesia: sensações de pressão (tato), temperatura, e dor percebidas pelos receptores localizados na pele e lábios, incluindo mucosa oral, língua e membrana periodontal ;

- Cinestesia: sensação de posição, movimento e tensão de partes do corpo percebidos através de nervos e órgãos nos músculos, tendões e juntas.

Já Oliveira [12] conceitua e exemplifica sensações somestéticas e sensações cinestésicas:

- Sensações somestéticas: terminações nervosas superficiais na pele, epiderme, derme e tecido subcutâneo. Nos alimentos, granulosidade, arenosidade, cristalinidade e floculação são consideradas sensações somestéticas.

- Sensações cinestésicas: correspondem ao movimento mecânico dos músculos resultantes do esforço excessivo feito pelos músculos da mão, maxilar ou língua e a sensação da força resultante (compressão, ruptura ou corte) sobre a amostra que está sendo manuseada ou mastigada etc. Firmeza, adesividade e viscosidade são sensações cinestésicas. Outro meio do uso da sensação cinestética é o toque ao alimento, como por exemplo, o exame de maturação de frutas. 
A textura é o principal atributo sensorial que se utiliza do sentido táctil para sua avaliação, embora possa ser avaliado também com o auxílio da audição e da visão. Trata-se de um conjunto das propriedades mecânicas, geométricas e de superfície de um alimento, que podem ser percebidas pelos receptores táteis, cuja sensação depende principalmente de sua deformação quando Ihe é aplicada uma pressão [4, 6].

Entre as propriedades mecânicas pode-se citar a dureza, a elasticidade, a viscosidade, a aderência e a coesão. Já as propriedades geométricas dizem respeito à forma, arranjo e dimensão das partículas no interior do alimento. Por último, as propriedades de superfície na boca envolvem forma como os constituintes dos produtos são libertados, e, tanto na pele quanto na boca, as sensações produzidas pela umidade e/ou o conteúdo de gordura do alimento [10].

Conforme Gularte [6], os órgãos envolvidos na avaliação da textura são:

- Palato e língua (da estrutura superficial da boca);

- Membrana periodontal (que envolve os dentes e as gengivas);

- Músculos e tendões utilizados na mastigação.

\subsubsection{Sentido Auditivo}

O sentido da audição é percebido através de receptores sensoriais localizados no ouvido humano. Este órgão exerce a função de converter uma fraca onda mecânica no ar em estímulos nervosos que são enviados ao cérebro, especificamente na porção que corresponde ao córtex auditivo, onde os diferentes ruídos são reconhecidos e interpretados [13].

Um determinado elemento vibrador gera uma onda sonora, que acarreta na variação da densidade ou da pressão do ar, ocorrendo compressão e rarefação. Com isso ocorre uma propagação de ondas progressivas, que atingem o ouvido, produzindo uma sensação sonora [14].

O ouvido humano é dividido em ouvido externo, médio e interno, e estruturas definidas como trompas de Eustáquio permitem que as vibrações cheguem até o ouvido interno [9].

Cada tipo de alimento é associado a sons específicos, ou seja, quando pensamos em um alimento, automaticamente conseguimos imaginar o som que ele irá produzir em função de suas características. É o caso da diferença 
esperada no som gerado durante a mastigação de um vegetal ao ser consumido cru ou cozido, ou da resposta sonora esperada ao consumir um alimento crocante como um biscoito, um salgadinho ou um snak. Isso significa dizer que os sons dos alimentos são comumente associados à sua textura, e o reconhecimento se dá em função da memória referente a experiências prévias do consumidor [9].

Gularte [6] evidencia que, além do som decorrente da textura de alguns alimentos, o som das bolhas de bebidas gaseificadas, como refrigerantes e espumantes também estão associados às memórias auditivas e são esperadas quando ocorre o consumo desse tipo de produtos.

\subsubsection{Demais condições que podem afetar as percepções}

A qualidade sensorial dos alimentos está diretamente relacionada às percepções interpretadas pelos julgadores, mas também recebe grande influência de condições fisiológicas e psicológicas, sendo resultante da interação entre o homem e o alimento que está avaliando. Portanto, pode-se inferir que as características sensoriais de um dado alimento podem variar entre os indivíduos e também pode ser influenciada pelo ambiente [10, 15].

Com relação aos indivíduos, existem fatores importantes que devem ser considerados no momento da escolha de um julgador [10]. O avanço da idade afeta negativamente a sensibilidade de percepção em todos os órgãos humanos, por isso normalmente considera-se uma faixa etária de alto potencial para avaliação da maioria dos alimentos é entre 18 e 50 anos, sendo que para salgadinhos, sucos e refrigerantes a faixa de 20 a 35 anos é mais adequada, e para a avaliação de doces é interessante utilizar julgadores com idade igual ou menor que 12 anos [6]. A fadiga ou adaptação sensorial, que já foi citada [6, 8, 9], tanto no caso dos sentidos do olfato, paladar e visão frente a estímulos prolongados, reduz a capacidade perceptiva dos julgadores, assim como é o caso da diminuição das percepções por "contraste", quando avalia-se um alimento com estímulo de maior intensidade antes de outro que apresenta menor intensidade [9].

Gularte [6] destaca que realizar avaliações sensoriais com fome ou em condição de plena saciedade, acarreta no aumento e na diminuição da sensibilidade do indivíduo, respectivamente, o que pode afetar a resposta dos 
julgadores. Por outro lado, o uso de medicamentos como antialérgicos, antibióticos histamínicos, e procedimentos como radioterapia e quimioterapia podem diminuir a capacidade sensorial. O sexo afeta a percepção em função dos hormônios reprodutivos de cada indivíduo, com isso, normalmente as mulheres apresentam maior sensibilidade que os homens, porém menor constância em função da variação hormonal, que ocorre de forma muito mais sutil nos homens. Já mencionados nos diferentes sentidos, existem anomalias gustativas, olfativas e visuais que diminuem a capacidade de percepção sensorial dos indivíduos [12].

Além dos fatores fisiológicos, segundo Stone et al. [16] são inúmeros os fatores psicológicos que podem influenciar a avaliação sensorial, induzindo a erros de avaliação ou a julgamentos tendenciosos por diferentes motivos:

- Resultantes de conhecimento prévio sobre o produto, gerando expectativa de encontrar atributos ou diferenças específicas com base nesse conhecimento (erro de expectativa);

- Pela tendência do julgador de atribuir sempre a mesma classificação por força do hábito (erro de hábito);

- Provadores que evitam os extremos das escalas de classificação (erro de tendência central);

- Quando várias amostras são avaliadas ao mesmo tempo, verificandose que os produtos são classificados como sendo muito diferentes um do outro e que a magnitude da diferença é bastante superior à esperada (erro contraste); entre outros.

\subsection{Condições dos testes}

Para alcançar a expectativa de obter as respostas de avaliações sensoriais de forma correta e significativa existe uma série de condições importantes a serem consideradas e seguidas. Entre elas é possível citar a estrutura laboratorial, bem como as características desejáveis do ambiente para a realização de testes; a correta forma de preparar e apresentar as amostras aos julgadores; e os critérios de seleção dos indivíduos que irão compor a equipe de julgadores para Análise Sensorial [1]. 


\subsubsection{Laboratório}

Exceto nos casos em que as avaliações sensoriais de alimentos envolvam testes diretos com consumidores, situação que permite adaptações, para os demais ensaios sensoriais faz-se necessário um local apropriado para sua condução, com estrutura planejada e construída para tal finalidade, além de condições específicas que o ambiente deve atender [17].

Para tanto, a escolha do local onde o laboratório será projetado deve apresentar um ambiente de fácil acesso para receber os julgadores, além de estar distante de zonas de barulho e odores [1]. O local para a realização das provas deve ser isento de ruídos externos; a iluminação deve ser uniforme e o mais próximo da luz natural, sendo recomendada a iluminação com lâmpadas fluorescentes; a temperatura agradável sendo o ideal em torno de 20 a $22{ }^{\circ} \mathrm{C}$, umidade relativa do ar entre 50 a $70 \%[9,17]$.

É de fundamental importância o controle geral da estrutura física das instalações laboratoriais, priorizando-se a busca pela naturalidade e neutralidade de quesitos como as cores do ambiente (incluindo paredes, chão, teto e móveis), iluminação, temperatura, ruídos, odores e ventilação, o que gera sensação de conforto dos julgadores em relação ao ambiente [9].

Segundo Dutcosky [1], existem estruturas mínimas que um laboratório de análise sensorial deve conter:

- uma área de testes onde as avaliações possam ser desenvolvidas individualmente em cabines ou em grupos de mesa redonda;

- uma área de preparação das amostras;

- um escritório;

- uma sala de estocagem de materiais;

- uma sala de espera para os julgadores.

Apesar de o layout dos laboratórios apresentarem inúmeras possibilidades de distribuição e estruturação, a Figura 3 demonstra o exemplo de um laboratório contendo todas as áreas descritas anteriormente. 


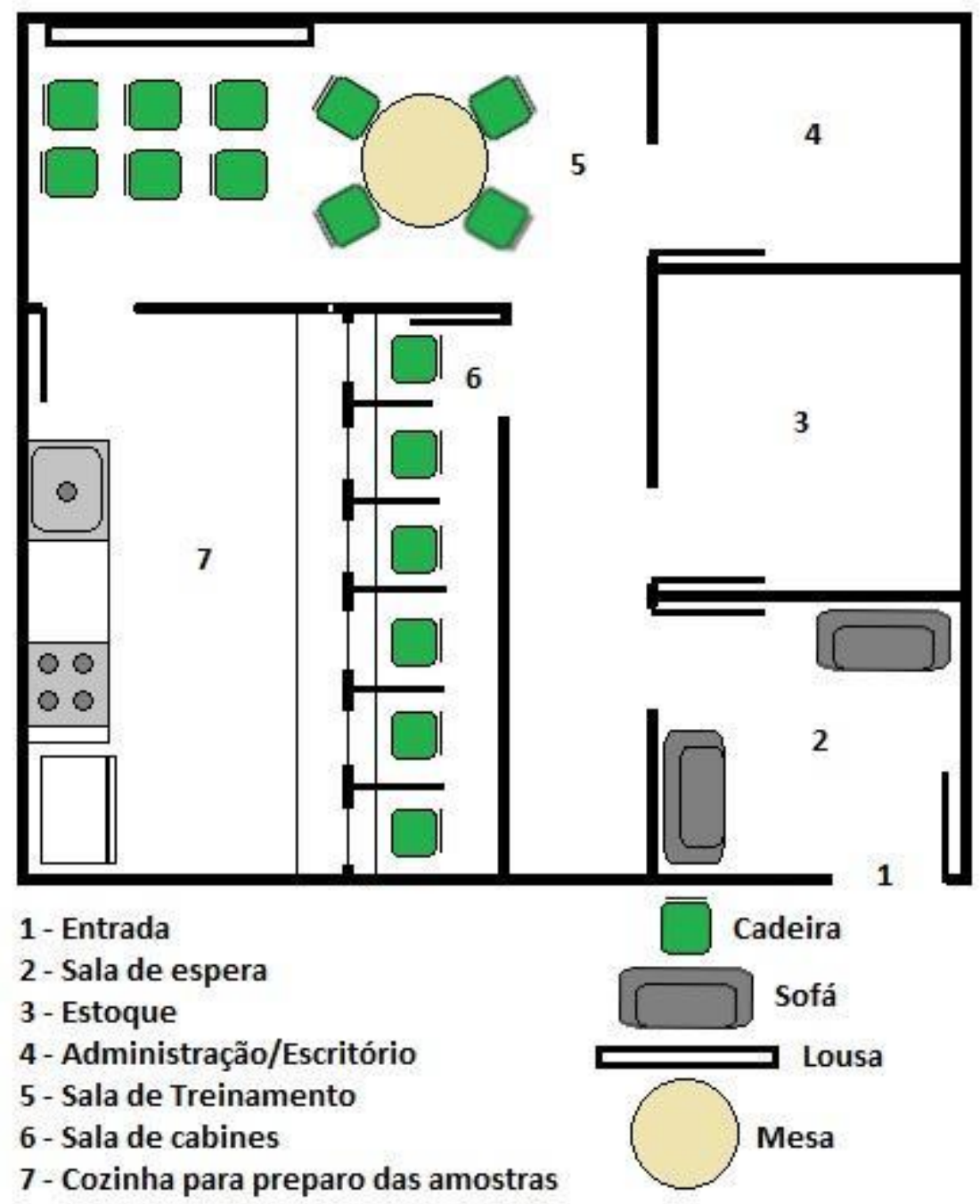

Figura 3. Layout de um laboratório de Análise Sensorial de Alimentos.

A sala de cabines é estrategicamente projetada com cabines individuais, para evitar interações entre os julgadores e possibilitar total concentração no momento das avaliações [17]. É recomendado que as cabines contenham cuspideiras para o descarte de amostras líquidas e que a iluminação seja controlada em cores, como azul ou vermelho, com a finalidade de mascarar a cor de determinados alimentos para testes específicos em que a cor ou a tonalidade não deve induzir o julgador a associá-la a outras características [6]. Além disso, as cabines devem ser planejadas de forma que seu acesso seja independente do local de preparo das amostras [17].

A área de preparo das amostras ser estruturada de forma a conter os equipamentos e utensílios necessários para o correto processamento das amostras para os testes sensoriais, como pias, fogão, refrigerador, freezer, 
microondas, processador, liquidificador, termômetro, balança, forno, bancadas e armários. Utensílios básicos, como recipientes, jarras, medidores, copos, talheres, pratos, entre outros, são necessários, podendo ser de material descartável, vidro, aço inoxidável ou porcelana [6, 9].

A sala de treinamento, onde serão realizados os treinamentos e reuniões com os julgadores deve encontrar-se em ambiente separado das cabines e também da sala de preparo de amostras e é aconselhável que contenha uma lousa ou quadro para anotação, explicação e planejamento de como será realizado o teste [9]. É importante dispor de mesa redonda para as ocasiões em que o grupo tem por objetivo treinamento e busca de consenso entre julgadores para análises descritivas, como é o caso de análise de perfis descritivos, discussão e padronização de procedimentos, além de caracterização de amostras de referência [1].

Ainda deverá existir um espaço separado do local de ensaios, porém próximo, com o objetivo da realização dos trabalhos administrativos, como a produção das fichas a serem utilizadas nos testes, planilhas para compilação de dados, tratamento dos resultados e elaboração de relatórios. Assim a estrutura básica de escritório se faz necessária, além de um ambiente destinado a receber clientes ou julgadores, quando necessário [17].

\subsubsection{Amostras}

Para realizar uma avaliação sensorial de um determinado produto alimentício é importante planejar as amostras a serem submetidas à análise com relação ao seu preparo e sua apresentação ao julgador. No que diz respeito ao preparo, as amostras devem seguir as indicações feitas pelo fabricante, de modo a serem disponibilizadas aos avaliadores sensoriais na apresentação mais próxima possível das condições habituais de consumo [18].

Entre os critérios importantes para a preparação e apresentação de amostras a serem utilizadas em Análise Sensorial, destaca-se a definição e padronização da quantidade e temperatura ideais para degustação [1]. Não é recomendado utilizar temperaturas superiores a $68{ }^{\circ} \mathrm{C}$ para alimentos servidos quentes, nem abaixo de $0 \stackrel{\circ}{\circ}$ para aqueles servidos frios, para não prejudicar a sensibilidade dos órgãos dos sentidos [6]. Alguns autores indicam o uso de termômetro para monitorar a temperatura dos alimentos, sugerindo como faixa 
recomendada de degustação de alimentos entre 7 e $70 \stackrel{\circ}{\mathrm{C}}$ [9]. Para tanto, a Tabela 2 mostra as faixas de temperatura ideais a serem aplicadas para a avaliação de alimentos específicos [13].

Tabela 2. Temperaturas ideais de diferentes alimentos para Análise Sensorial segundo o Instituto Adolfo Lutz [13].

\begin{tabular}{lc}
\hline \multicolumn{1}{c}{ Alimento } & Temperatura $\left({ }^{\circ} \mathrm{C}\right)$ \\
\hline Cerveja & $4-5$ \\
Bebidas carbonatadas & $6-10$ \\
Leite & $7-10$ \\
Sorvetes & $10-12$ \\
Vinhos & 20 ou gelados \\
Água & $20-22$ \\
Pão & $20-22$ \\
Manteiga, margarina e maionese & $20-22$ \\
Licores destilados & $20-22$ \\
Alimentos quentes & $35-45$ \\
Óleos comestíveis & $68-71$ \\
Sopa & $68-71$ \\
Café & $68-71$ \\
Chá & $60-71$ \\
\hline
\end{tabular}

No que diz respeito à quantidade das amostras, as mesmas devem conter em sua apresentação uma fração representativa do produto, preservando todas as características sensoriais importantes de serem analisadas. Tal quantidade pode variar de acordo com o tipo de produto, o método utilizado e a habilidade dos julgadores, que podem ser treinados ou não. Apesar disso, para diferentes tipos de alimentos existem recomendações 
padronizadas de quantidades a serem respeitadas. Para amostras líquidas utiliza-se entre 15 e $25 \mathrm{~mL}$, enquanto para amostras sólidas, entre 15 e $20 \mathrm{~g}$. Alguns produtos ainda apresentam especificações, o que é o caso de grãos que é indicada a apresentação de $10 \mathrm{~g}$; cereal cozido de 10 a $15 \mathrm{~g}$; frutas ou vegetais cozidos $20 \mathrm{~g}$; frutos in natura $30 \mathrm{~g}$ e carne entre 15 e $20 \mathrm{~g}$. No caso das amostras sólidas, as mesmas podem ser apresentadas em seu formato natural ou em pequenos pedaços, dependendo das características do produto, de forma a facilitar a degustação por parte do julgador, sendo fundamental que todas as unidades amostrais mantenham os mesmos padrões de formato, porção, quantidade, tamanho, espessura e tempo de cocção [9].

O número máximo de amostras a serem apresentadas em uma análise deve ser definido descartando-se a possibilidade da ocorrência de fadiga sensorial, e segundo Dutcosky [1] depende de uma série de fatores, como:

- natureza do produto (ex.: sorvetes - máximo seis amostras);

- intensidade e complexidade da propriedade sensorial que está sendo julgada;

- experiência do julgador;

- tipo de teste que está sendo utilizado;

- quantidade disponível do produto e tempo que se dispõe.

No momento da análise as amostras devem ser apresentadas em recipientes próprios ou aqueles comumente utilizados durante as refeições, e os mesmos devem ser codificados com números aleatórios, sendo normalmente 3 dígitos escolhidos ao acaso, com o objetivo de evitar julgamentos tendenciosos [6]. O horário da avaliação também é importante, visto que não é aconselhado aplicar testes sensoriais nas duas horas seguintes ao horário de almoço [17].

\subsubsection{Seleção da Equipe de Julgadores}

A seleção dos julgadores que irão compor a equipe sensorial, por razões econômicas, pode ser realizada no ambiente de trabalho. No caso de indústrias de alimentos, é possível recrutar recursos humanos de todos os setores, que estarão nas proximidades do ambiente de avaliação e terão fácil acesso. Não é indicado recrutar para as equipes de análise indivíduos envolvidos na 
elaboração dos produtos, preparo das amostras ou que apresentem alergia alimentar, hábitos de não consumir o produto a ser analisado ou desgostar do mesmo [6].

Bento et al. [9] indicam que um levantamento de dados inicial deve ser realizado com os possíveis julgadores e uma série de quesitos devem ser levados em consideração, como [9]:

- Interesse na análise sensorial;

- Perfil de cooperação e motivação para executar as análises;

- Demonstração de curiosidade intelectual e estabilidade emocional;

- Apetite normal e disponibilidade em provar diferentes produtos;

- Boa saúde (sem alergias, resfriados, fadiga ou outras doenças).

Com o objetivo de testar as habilidades de sensibilidade de percepções sensoriais, testes devem ser aplicados aos candidatos a julgadores, sendo que os resultados devem ser avaliados estatisticamente e utilizados como critério de aceitação ou rejeição de cada membro. Entre os testes pode-se citar o de reconhecimento de odores, o de identificação de gostos básicos e o teste de detecção de diferença ou similaridade. No caso deste, são apresentadas 3 amostras ao candidato, sendo duas iguais e uma diferente, e o mesmo deverá indicar qual é a amostra diferente ou quais são as amostras iguais [1].

Os candidatos aptos para compor a equipe de julgadores poderão ser consumidores normais (sem treinamento e sem conhecimento das técnicas sensoriais), treinados (que passarão por etapas de treinamento posterior) ou experts (treinados e muito experientes em um alimento específico) [6].

Nos próximos capítulos deste livro serão abordadas de forma detalhada os testes que podem ser empregados para a seleção dos julgadores, bem como a gama de testes sensoriais clássicos que podem ser empregados para avaliação sensorial de alimentos.

\section{Considerações Finais}

Compreender os conceitos e fundamentos da Análise Sensorial de Alimentos, como conhecer as principais terminologias utilizadas, 0 funcionamento dos sentidos sensoriais humanos e sua forma de reconhecimento das características dos alimentos, bem como a estrutura e as 
condições do ambiente laboratorial, o preparo e apresentação das amostras e a seleção da equipe de julgadores sensoriais, é de extrema importância para o entendimento e aplicação dos diferentes métodos sensoriais utilizados para a avaliação de diferentes produtos alimentícios.

Portanto, este capítulo serve de base para uma melhor assimilação das informações referentes à Análise Sensorial apresentadas nos capítulos que seguem nesta obra.

\section{Referências}

[1] Dutcosky S.D. Análise sensorial de alimentos. 4 ed. Curitiba: Champagnat, 2013. 536p.

[2] Lucia S.M.D., Minim V.P.R., Carneiro J.D.S. Análise sensorial de alimentos. In: Minim V.P.R. (ed) Análise sensorial: estudos com consumidores. editora. UFV; 2010, p. 13-49. Viçosa, Brasil.

[3] Torres-Moreno M., Tarrega A., Torrescasana E., Blach C. Influence of label Information on dark chocolate acceptability. Appetite 2012; 58(2): 665-671.

[4] Teixeira L.V. Análise Sensorial na Indústria de Alimentos. Revista do Instituto de Laticínios Cândido Tostes 2009; 366(64): 12-21.

[5] ABNT - Associação Brasileira de Normas Técnicas. Métodos de análise sensorial dos alimentos e bebidas - classificação. ABNT NBR 12994: Rio de Janeiro, 1993.

[6] Gularte M.A. Manual de Análise Sensorial de Alimentos. Pelotas: Editora Universidade Federal de Pelotas, 2009. 106 p.

[7] Silva A.C.S.M. Introdução à Análise Sensorial de gêneros alimentícios e sua aplicação na indústria alimentar. Universidade do Porto, Porto, 41 p., 2015.

[8] ABNT - Associação Brasileira de Normas Técnicas. Análise Sensorial Vocabulário. ABNT NBR ISO: 5492: Rio de Janeiro, 2017.

[9] Bento R.A., Andrade S.A.C., Silva A.M.A.D. Análise Sensorial de Alimentos. Pernambuco: Editora da Universidade Federal Rural de Pernambuco, 2013. $142 \mathrm{p}$.

[10] Alvelos H.M.P.P.D. Análise, Desenvolvimento e Teste de Métodos e Técnicas para Controlo Estatístico em Análise Sensorial, Universidade do Porto, 94 p., 2002, acesso em 23 de fevereiro de 2021 em: http://repositorioaberto.up.pt/handle/10216/12427. 
[11] Almeida A.T.M.S. A Genética e a Fisiologia dos Sabores - O treino do paladar: marcadores precoces de uma alimentação saudável para a vida, Universidade do Porto, p. 2-4, 2010. Acesso em 23 de fevereiro de $2021 \mathrm{em}$ : http://repositorioaberto.up.pt/bitstream/10216/54777/3/137776_1011TCD11.pdf [12] Oliveira A.F. Análise Sensorial dos Alimentos. Londrina/PR: Universidade Tecnológica Federal do Paraná - Curso de Tecnologia em Alimentos. 65 p., 2010.

[13] Instituto Adolfo Lutz. Análise Sensorial de Alimentos capítulo VI. In:Instituto Adolfo Lutz. Métodos Físico-Químicos para Análise de Alimentos, 4⿳亠丷a Edição, $1^{a}$ Edição Digital. p. 279-320, 2008.

[14] ANTARCTICA. Curso Básico de Formação de Degustadores. Ribeirão Preto: Cervejaria Antarctica, 108 p., 1995.

[15] Custódio Y.N., Lara J.E., Vasconcelos M.C.R.L., Locatelli R.L. Análise sensorial: aplicação a um evento gastronômico/Sensory analysis: application for a gastronomic event. Podium 2015, 4(1): 32.

[16] Stone H, Rebecca N.B, Heather A.T. Sensory Evaluation Practices, 4 ${ }^{\mathrm{a}}$ edição. Academic Press 2012, p. 446.

[17] Noronha J.F. Análise Sensorial - Metodologia. Material de apoio às aulas de Análise Sensorial, Escola Superior Agrária de Coimbra: Coimbra; 2003. v. 1 , p. 75.

[18] ABNT - Associação Brasileira de Normas Técnicas. Sensory AnalysisMethodology-General guidance for conducing hedonic tests with consumers in a controlled area. ABNT ISO 11136: Rio de Janeiro, 2014.

\section{Autores}

Michelle Barboza Nogueira*

Coordenadoria do Curso de Bacharelado em Ciência e Tecnologia de Alimentos, Instituto Federal do Espírito Santo, Campus Venda Nova do Imigrante, 29375-000, Venda Nova do Imigrante, Brasil.

*Autor para correspondência: mimibnogueira@gmail.com 